Article

\title{
Public Engagement Provides First Insights on Po Plain Ant Communities and Reveals the Ubiquity of the Cryptic Species Tetramorium immigrans (Hymenoptera, Formicidae)
}

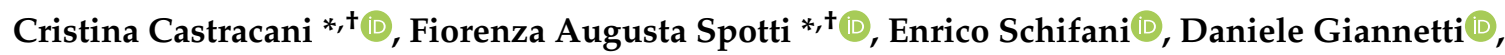 \\ Martina Ghizzoni, Donato Antonio Grasso $¥ \mathbb{D}$ and Alessandra Mori $\ddagger$ \\ Department of Chemistry, Life Sciences \& Environmental Sustainability, University of Parma, Parco Area delle \\ Scienze, 11/a, 43124 Parma, Italy; enrico.schifani@unipr.it (E.S.); daniele.giannetti@unipr.it (D.G.); \\ martina.ghizzoni@unipr.it (M.G.); donato.grasso@unipr.it (D.A.G.); alessandra.mori@unipr.it (A.M.) \\ * Correspondence: cristina.castracani@unipr.it (C.C.); fiorenzaaugusta.spotti@unipr.it (F.A.S.) \\ + Co-first authors. \\ $\ddagger$ Co-last authors.
}

Received: 13 August 2020; Accepted: 2 October 2020; Published: 7 October 2020

Simple Summary: Public involvement in biodiversity research in the form of Citizen Science is a powerful tool to improve our understanding of the natural world, and it is especially suitable for the study of heavily populated environments. Ants' ubiquity and diversity, their role as ecological bioindicators, and the fact that most species can easily be sampled makes them ideal candidates for this kind of studies. In the framework of the international School of Ants citizen science project, we joined the "BioBlitz Lombardia" in which citizens are invited to collect biodiversity data on several parks from Lombardy (Po Plain, Italy). As a result, we recorded 30 ant species and obtained a first characterization of the region's ant assemblages. We studied their patterns of variation in relation with the ecological difference between the studies sites, which ranged from urban to subalpine areas. In addition, we detected the presence of a cryptic species (Tetramorium immigrans) whose distribution and identity were only recently clarified. It likely represents an under-recorded introduced species in the region. Advantages and critical aspects of using CS methodology for the study of biodiversity are discussed in light of our experience.

Abstract: Ants are considered a useful model for biodiversity monitoring and several of their characteristics make them promising for citizen science (CS) projects. Involving a wide range of public figures into collecting valuable data on the effect of human impact on ant biodiversity, the School of Ants (SoA) project represents one of the very few attempts to explore the potential of these insects in CS. Through the collaboration with the "BioBlitz Lombardia" project, we tested the SoA protocol on 12 Northern Italy parks, ranging from urban green to subalpine protected sites. As a result, we obtained some of the very first quantitative data characterizing the ants of this region, recording 30 species and highlighting some interesting ecological patterns. These data revealed the ubiquitous presence of the recently taxonomically defined cryptic species Tetramorium immigrans, which appears to be probably introduced in the region. We also discuss advantages and criticisms encountered applying the SoA protocol, originally intended for schools, to new categories of volunteers, from BioBlitz participants to park operators, suggesting best practices based on our experience.

Keywords: community science; citizen science; BioBlitz; School of Ants; ant biodiversity; exotic species 


\section{Introduction}

Public engagement in scientific projects has been known since the beginning of the 20th century [1], but its value has been only recently recognized by the scientific community that names citizen science (CS) this collaboration between scientists and citizens [1-4]. Citizen science provides many advantages to scientists, allowing them to gather a high amount of data with reduced time and economic costs, and, at the same time, it enhances citizen awareness and education over scientific practices and topics [2,5-7].

Recently, the expression "community science" was proposed as a more inclusive replacement of the widely used expression "citizen science," in the attempt to highlight that all volunteers can participate to scientific projects, regardless of their origin and background [8,9]. Nevertheless, following the UNESCO Recommendation on Open Science [10], Wehn and colleagues [11] maintained the term "citizen science," making it a pillar of Open Science as it promotes social inclusion, scientific citizenship and sustainability. Moreover, the expression "community science" is often used in relation to projects that are led by the community itself to address a collective issue, sometimes even without the help of experts [12]. As a consequence, in this paper, we decided to keep the consolidated term "citizen science" to enhance clarity throughout the text and avoid confusion in relation to literature we referred to. However, we intend the word "citizen" with the broad sense of "nonspecialist participant."

CS projects can effectively contribute to attain most of the Sustainable Development Goals (SDGs) scheduled by United Nations in the 2030 Agenda for sustainable development [13-15]. In fact, in accordance with SDG n. 15 "Life on land," many CS projects aim at monitoring biodiversity for conservation purposes over regional to continental extents and decadal time scales $[7,15,16]$. Biodiversity preservation appears as urgent as ever due to the ongoing environmental crisis [17], therefore, CS offers key opportunities to collect rapidly fine-grain data on a broad spatial scale and to raise public awareness on this issue $[4,5,7,16,18-21]$.

A critical point for monitoring biodiversity in CS projects is selecting a target group easy to observe and representative of its ecosystem. For this purpose, ants (Hymenoptera, Formicidae) can be a suitable model because they are abundant and widespread in most terrestrial ecosystems and easy to detect and collect also for nonexperts. Moreover, ants belong to an extremely diverse family of insects and, thus, they are a good model to explain the meaning of the term "biodiversity" to citizens. Finally, ants are often keystone species in their ecosystems and they can respond quickly to environmental changes, so they are successfully used as bioindicators in various contexts [22-29].

Due to the growth of urbanization worldwide, biodiversity conservation in the cities has become a major concern [30-32] and it is part of the SDG n. 11 "Sustainable cities and communities" [13]. From this perspective, monitoring ant communities can be critical to assess the impact of human activities on urban ecosystems, but few data are currently available, mainly referring to the American and Australian continents [33-38]. In Italy, the role of ants as bioindicator is still poorly studied and the few researches were conducted in protected natural areas [39-44].

First launched in the United States [45,46] and then spread to other countries [47-49], the citizen science project "School of Ants" (SoA) aims to fill this knowledge gap, studying urban ant biodiversity through large public involvement. In Italy, the project, led by the Myrmecology Lab (University of Parma-UNIPR), has further developed around the need of counteracting the scarcity of practical scientific experiences within Italian schools and it has now flown into the project "School of Ants: a scuola con le formiche" (SoA: learning with the ants). This lack of an inquiry-based science education is likely to be the main cause of students' low interest for scientific subjects and, subsequently, for scientific professions [50,51]. In this context, the SoA project offers to students and teachers a hands-on science experience with the ongoing support of a team of researchers. Moreover, the SoA project provides participants with a very simple sampling protocol to address the data quality issue, whereas researchers perform the critical step of species identification. The last step is the production of feedback for participants: results are shown and directly discussed with volunteers or through emails, the official website, and the social networks. After a pilot phase focused on the ant fauna of the urban area of Parma (Emilia-Romagna, Northern Italy) (see box "School of Ants goes global: 
International module of SoA in Parma, Italy" in [46]), the project eventually spread nationwide thanks to the collaboration with the Science Museum of Trento [52]. While the initial results had depicted the commonness of the ant Tetramorium caespitum (Linnaeus, 1758) [46], new research questions arose from recent taxonomic advancements. Since the split of the traditional concept of $T$. caespitum into a complex of several species characterized by different ecology and natural history [53,54], the distribution of the complex could now be studied on a nationwide scale thanks to the SoA greater geographic reach.

In 2018, the SoA met the "BioBlitz Lombardia" (BBL), a project managed by a network of parks [55] and the Lombardy Region [56]. Traditional BioBlitz events aim at discovering and recording the presence of as many species of plants, animals, and fungi as possible within a set location, over a defined period (usually $24 \mathrm{~h}$ ) and they are run by professional naturalists with public participation [57-59]. The BBL project does not fully comply with the traditional BioBlitz definition because it was not held continuously during $24 \mathrm{~h}$, but during different time slots along a weekend, depending on each park's choice. However, it was a collaborative monitoring event where nonspecialist volunteers were guided by experts to discover local biodiversity and to upload the records on a global dataset platform [60]. On one hand, the BBL was looking for a taxonomic group that could be found in all the parks in order to compare data along different parks and to give an additional cohesive element to the network. On the other hand, the SoA was looking for new categories of volunteers to recruit in order to collect more data from new sampling sites. As a result, sampling through the SoA protocol was conducted in the most anthropogenic areas of some parks adhering to the BBL 2018 to keep the SoA focus on urbanized spots. According to CS best practices [61], participants received feedback on data they collected, as the checklist of the ant species and information on their abundance and distribution.

As data on ant communities in the study areas were out of date and incomplete [62], this work aimed mainly to: (i) test the effectiveness of the SoA project in involving a new category of volunteers as the people attending the biodiversity BioBlitzes; (ii) gather data on species abundance in order to provide an updated, even if not comprehensive, checklist of the ant species and to compare the ant communities of different parks; (iii) obtain new insights on the distribution of T. caespitum complex species in Italy.

\section{Materials and Methods}

\subsection{Project Development}

The project was first presented on February 2018 during the workshop "BioBlitz Lombardia: a review of the past editions and future plans" organized by Lombardy Region, A.R.E.A. Parchi, Oglio Sud Park, and Le Bine Regional Reserve. Addressed to the representatives of the parks joining the A.R.E.A. Parchi network, the workshop was the first meeting between the researchers of the SoA project and the organizers of the BBL. In this occasion, goals of both SoA and BBL were presented and a first draft of the joint project "SoA at BioBlitz Lombardia 2018" was attained.

In the following weeks, a participation list from parks of the A.R.E.A. Parchi network was compiled and Parco Nord Milano organized a training meeting at the end of March 2018 (see Table 1; Table S1). During the meeting, the park representatives were trained by the UNIPR researchers on the SoA sampling protocol with a specific attention to the sampling sites. Le Bine Regional Reserve was used as a study model and a simulation of the sampling sites selection was proposed and analyzed. Parco Nord Milano area was then used for a demonstrative sampling: all the participants were allowed to use one kit and they were also trained for the use of the iNaturalist App. Finally, each participant received the material for setting a SoA point during the BBL 2018: 10 ant sampling kits, a set of brochures on SoA project, and a set of brochures about the project "SoA at BBL 2018" for sharing with BioBlitz participants. In order to keep update the participants at the meeting, a mailing list was created and a cloud was used for sharing documents. 
Table 1. List of the sampling sites. The last column shows the total number of collected kits for each site.

\begin{tabular}{lcccc}
\hline \multicolumn{1}{c}{ Site Name } & Tag & Latitude & Longitude & Baits \\
\hline 1. Adda Nord Park & Add & $45^{\circ} 27^{\prime} 49^{\prime \prime} \mathrm{N}$ & $9^{\circ} 28^{\prime} 33^{\prime \prime} \mathrm{E}$ & 48 \\
\hline 2. Campo dei Fiori Park & Fiori & $45^{\circ} 53^{\prime} 10^{\prime \prime} \mathrm{N}$ & $8^{\circ} 42^{\prime} 28^{\prime \prime} \mathrm{E}$ & 24 \\
\hline 3. Serio Park & Ser & $45^{\circ} 31^{\prime} 35^{\prime \prime} \mathrm{N}$ & $9^{\circ} 43^{\prime} 51^{\prime \prime} \mathrm{E}$ & 80 \\
\hline 4. Groane Park & Gro & $45^{\circ} 37^{\prime} 14^{\prime \prime} \mathrm{N}$ & $9^{\circ} 5^{\prime} 36^{\prime \prime} \mathrm{E}$ & 80 \\
\hline 5. Monte Barro Park, Loc. Camporeso & $\mathrm{BCa}$ & $45^{\circ} 49^{\prime} 28^{\prime \prime} \mathrm{N}$ & $9^{\circ} 22^{\prime} 11^{\prime \prime} \mathrm{E}$ & 40 \\
\hline 6. Monte Barro Park, Loc. Eremo & $\mathrm{BEr}$ & $45^{\circ} 49^{\prime} 57^{\prime \prime} \mathrm{N}$ & $9^{\circ} 22^{\prime} 45^{\prime \prime} \mathrm{E}$ & 40 \\
\hline 7. Nord Milano Park & $\mathrm{NMi}$ & $45^{\circ} 32^{\prime} 16^{\prime \prime} \mathrm{N}$ & $9^{\circ} 12^{\prime} 41^{\prime \prime} \mathrm{E}$ & 64 \\
\hline 8. Oglio Sud Park, Le Bine Reserve & $\mathrm{LBin}$ & $45^{\circ} 8^{\prime} 17^{\prime \prime} \mathrm{N}$ & $10^{\circ} 26^{\prime} 9^{\prime \prime} \mathrm{E}$ & 72 \\
\hline 9. Valle Lambro Park, Loc. Brianza & $\mathrm{LaBr}$ & $45^{\circ} 41^{\prime} 58^{\prime \prime} \mathrm{N}$ & $9^{\circ} 17^{\prime} 13^{\prime \prime} \mathrm{E}$ & 40 \\
\hline 10. Valle Lambro Park, Loc. Villa Campello & $\mathrm{LaCa}$ & $45^{\circ} 39^{\prime} 22^{\prime \prime} \mathrm{N}$ & $9^{\circ} 15^{\prime} 41^{\prime \prime} \mathrm{E}$ & 32 \\
\hline 11. Basso Brembo Park & $\mathrm{Bre}$ & $45^{\circ} 37^{\prime} 12^{\prime \prime} \mathrm{N}$ & $9^{\circ} 33^{\prime} 50^{\prime \prime} \mathrm{E}$ & 80 \\
\hline 12. PLIS Monte Canto e Bedesco & $\mathrm{CaBe}$ & $45^{\circ} 42^{\prime} 1^{\prime \prime} \mathrm{N}$ & $9^{\circ} 31^{\prime} 45^{\prime \prime} \mathrm{E}$ & 32 \\
\hline 13. Bosco Fontana Natural Reserve & Fon & $45^{\circ} 13^{\prime} 3^{\prime \prime} \mathrm{N}$ & $10^{\circ} 45^{\prime} 10^{\prime \prime} \mathrm{E}$ & 48 \\
\hline 14. Valpredina-Misma Natural Reserve & VaM & $45^{\circ} 43^{\prime} 3^{\prime \prime} \mathrm{N}$ & $9^{\circ} 48^{\prime} 55^{\prime \prime} \mathrm{E}$ & 80 \\
\hline
\end{tabular}

The BBL 2018 edition took place on 19 and 20 May 2018 and all the ants were sampled in those 2 days. During the months of June and July, all the samples were sent to the Myrmecology Lab.

From July to November 2018, all the ants were identified and each park received a set of results that they could share with the BioBlitz volunteers: a check list of the sampled species, an identity card for each species, a dataset recording the number of baits containing the species collected in the park (species frequencies), and a set of pictures of the specimen to be uploaded in the iNaturalist platform.

In December 2018, a final workshop was organized by Lombardy Region and A.R.E.A. Parchi in order to show and discuss the achievements in terms of both scientific results and good practices to suggest.

\subsection{Sampling}

During BBL 2018, each park participating to the SoA project set up a SoA point where park operators explained to visitors the aims of the project, recruited volunteers, and helped them to apply the protocol for ant collection properly. The Myrmecology Lab provided each park with 10 collection kits and with the instructions on how to use them. Park operators were invited to choose one or two sampling sites in anthropogenic areas within the park (e.g., near the visitor center or other buildings), and to use at least $5 \mathrm{kits}$ at the same site, that is a place defined by the same geographical coordinates. The sampling protocol was the same described as "modified SoA protocol" in Lucky et al. 2014 (see box "School of Ants goes global: International module of SoA in Parma, Italy"). A kit contained 8 baits consisting of 12-mL falcon tubes ( 4 with green caps and 4 with yellow caps) filled with $4 \mathrm{~mL}$ of cookie crumbs for attracting ants and a data collection sheet to fill with some collector personal data and environmental/weather information (Figure 1). Volunteers were asked for using a kit as follows: 1. opening and placing the 4 green-capped baits in vegetated areas (e.g., on the grass or at the base of a tree); 2 . opening and placing the 4 yellow capped baits in areas without vegetation (e.g., on concrete surfaces or paved areas); 3. waiting 1 hour and, in the meanwhile, filling the data collection sheet; 4 . collecting all the baits, capping them, and returning them to park operators together with the compiled data collection sheet. Twelve parks were involved in the SoA Project and 14 sites were sampled during BBL 2018 (Table S1). 


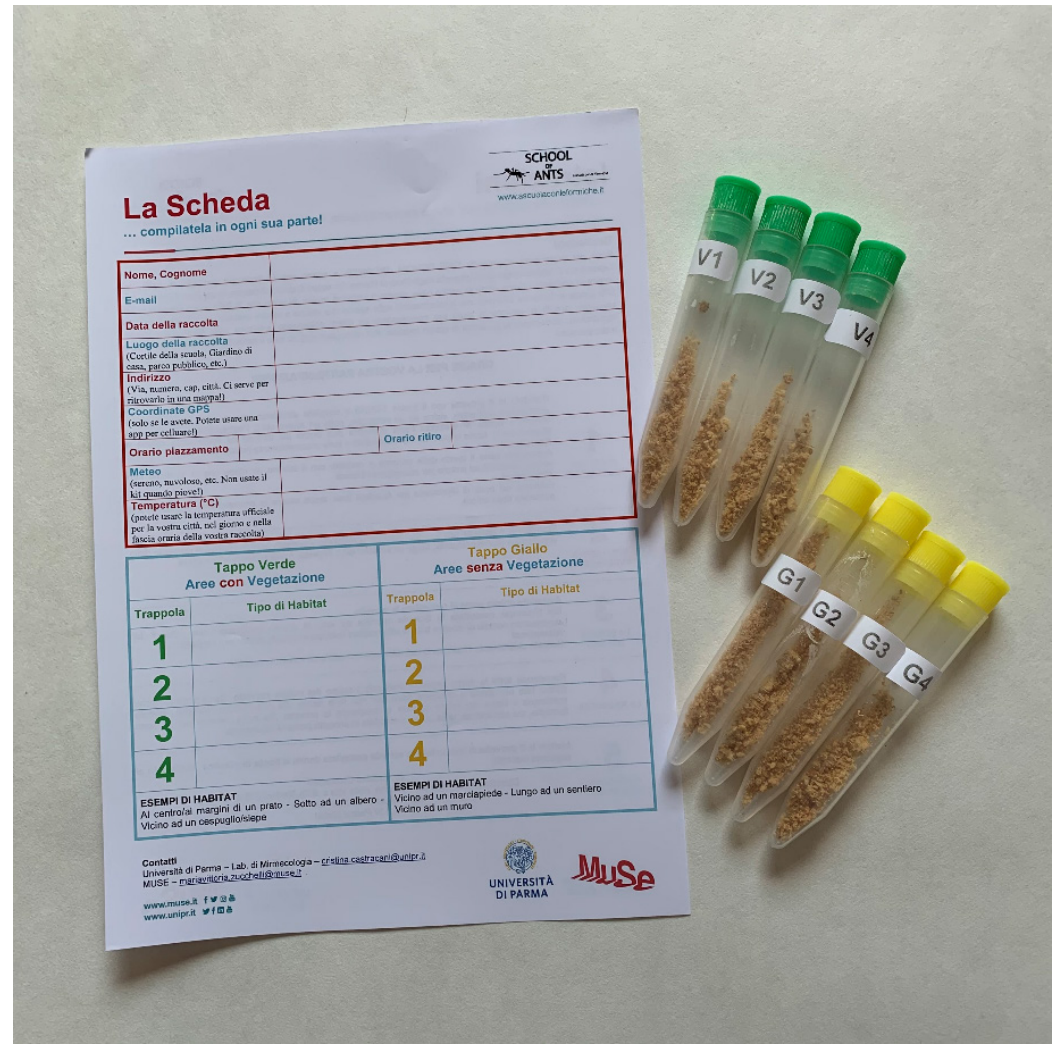

Figure 1. The ant collection kit: the data collection sheet (on the left) and the 8 baits (on the right).

\subsection{Species Identification}

Specimens were examined under a ZEISS Stemi 508 stereoscopic microscope (5-200× magnification range) with the asylum of an Axiocam Erc 5s and ZEISS ZEN core software used to take morphometric measurements. They were identified according to the following keys [63-65]. Tetramorium species belonging to the caespitum complex were identified according to the key provided by Seifert [64]: morphometric measurements were taken up to 2 workers per bait, assuming multiple specimens belonged to the same colony. All specimens were finally stored in the ant collection of the Myrmecology Lab.

\subsection{Statistical Analyses}

Statistical analyses were performed using the software R 3.5.2 and RStudio 1.1.463 [66]. Analyses were carried out on two datasets: Bulleted lists look like this:

- Full Dataset (FDataset) - This dataset contains data (species richness and abundance) from all the kits employed during BBL

- Standardized Dataset (StdDataset) - This dataset was created as a subset of the previous one with the aim of standardizing the sampling effort among different sites. We excluded data from sites in which less than 4 kits (32 baits) were employed. Moreover, for all the sites where more than 6 kits were used, we randomly selected only 6 kits ( 48 baits) per site.

FDataset was used for computing species accumulation curves of each site. The curves were plotted by considering the presence/absence of the ant species in each bait and using the specaccum () function of the Vegan R package [67]. 
Data from StdDataset were used to compare sites through the Nonmetric Multidimensional Scaling (NMDS). The average number of baits in which the species were found in each site was used in the analysis, and the metaMDS () and envfit () functions of Vegan R package were used for computation [62]. For each site, the StdDataset was used for calculating species richness and the following biodiversity indices: Simpson's Diversity Index (1-D), Shannon Diversity Index ( $\left.\mathrm{H}^{\prime}\right)$, and Species Equitability Index $(\mathrm{EH})[68,69]$. All indices were calculated based on frequencies (i.e., the number of baits in which each species was found). The same dataset was then used for calculating the Sørensen-Dice Similarity Index expressed as the mean value among all the possible comparisons with every other site [70,71].

\section{Results}

Data from the FDataset (768 baits from 14 sites) recorded the presence of 30 ant species belonging to 3 subfamilies: Dolichoderinae (1 sp.), Formicinae (12 spp.), and Myrmicinae (17 spp.) (Table 2 and Table S2). Eleven of these species were new to the Italian SoA project. The most speciose genera were Lasius Fabricius, 1804 (5 spp.), and Temnothorax Mayr, 1861 (5 spp.), followed by Camponotus Mayr, 1861 (4 spp.), and Myrmica Latreille, 1804 (4 spp.). Concerning site biodiversity, we recorded from 5 to 14 species per site (Table S2).

Table 2. Checklist of the ant species identified during BioBlitz Lombardia (BBL) 2018.

\begin{tabular}{|c|c|c|c|}
\hline Subfamily & Dolichoderinae & Formicinae & Myrmicinae \\
\hline Species & $\begin{array}{c}\text { Tapinoma subboreale } \\
\text { Seifert, } 2012\end{array}$ & $\begin{array}{c}\text { Camponotus fallax (Nylander, 1856) } \\
\text { Camponotus lateralis (Olivier, 1792) } \\
\text { Camponotus ligniperda (Latreille, 1802) } \\
\text { Formica clara Forel, 1886 } \\
\text { Formica cunicularia Latreille, 1798 } \\
\text { Formica gagates Latreille, 1798 } \\
\text { Lasius distinguendus (Emery, 1916) } \\
\text { Lasius emarginatus (Olivier, 1792) } \\
\text { Lasius fuliginosus (Latreille, 1798) } \\
\text { Lasius niger (Linnaeus, 1758) } \\
\text { Lasius paralienus Seifert, 1992 } \\
\text { Plagiolepis pygmaea (Latreille, 1798) }\end{array}$ & $\begin{array}{c}\text { Aphaenogaster subterranea (Latreille, 1798) } \\
\text { Crematogaster scutellaris (Olivier, 1792) } \\
\text { Messor ibericus Santschi, 1931 } \\
\text { Monomorium monomorium Bolton, 1987 } \\
\text { Myrmica hellenica Finzi, 1926 } \\
\text { Myrmica rubra (Linnaeus, 1758) } \\
\text { Myrmica sabuleti Meinert, 1861 } \\
\text { Myrmica specioides Bondroit, 1918 } \\
\text { Pheidole pallidula (Nylander, 1849) } \\
\text { Solenopsis fugax (Latreille, 1798) } \\
\text { Temnothorax flavicornis (Emery, 1870) } \\
\text { Temnothorax lichtensteini (Bondroit, 1918) } \\
\text { Temnothorax nylanderi (Foerster, 1850) } \\
\text { Temnothorax parvulus (Schenck, 1852) } \\
\text { Temnothorax unifasciatus (Latreille, 1798) } \\
\text { Tetramorium caespitum (Linnaeus, 1758) } \\
\text { Tetramorium immigrans Santschi, 1927 }\end{array}$ \\
\hline
\end{tabular}

The most widespread species was T. immigrans, collected in all 14 sites, whereas the following species were recorded in 1 site only: C. fallax, C. lateralis, C. ligniperda, F. clara, L. distinguendus, L. fuliginosus, M. ibericus, T. flavicornis, and P. pallidula (Figure 2-blue bars and Table S2).

The species accumulation curves showed that no complete plateau was reached in any of the sites, although in most sites, the curves reduced their increasing trend around 40 baits (Figure 3). Therefore, in the StdDataset, all data from site 2 as well as some data from sites 3, 4, 7, 8, 11, and 14 were removed.

Data from the StdDataset (568 baits from 13 sites) recorded the presence of 28 ant species. Concerning site biodiversity, we recorded from 5 to 14 species per site. Camponotus, Lasius, Myrmica, and Temnothorax were still the richest genera, while the rarest species were the same of the FDataset except for the absence of L. fuliginosus and T. flavicornis (Figure 2; Table S2). Tetramorium immigrans was again present in all 13 sampling sites, occurring on average in 12\% of the baits per site (Figure 4 and Table S2). 


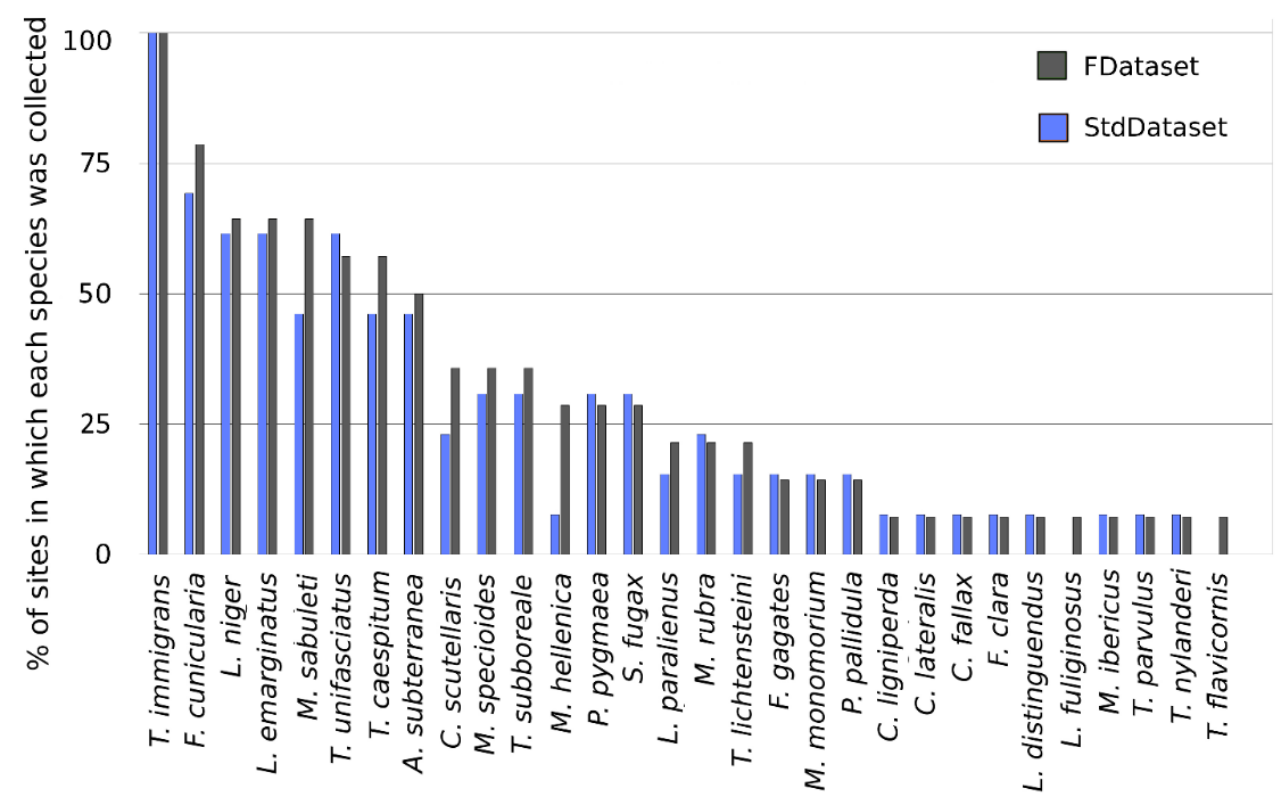

Figure 2. Distribution of ant species along the sampling sites. In gray, data from the FDataset $(\mathrm{N}=14)$ and in blue, data from the StdDataset $(\mathrm{N}=13)$. Species are listed according a decreasing gradient calculated from the FDataset.

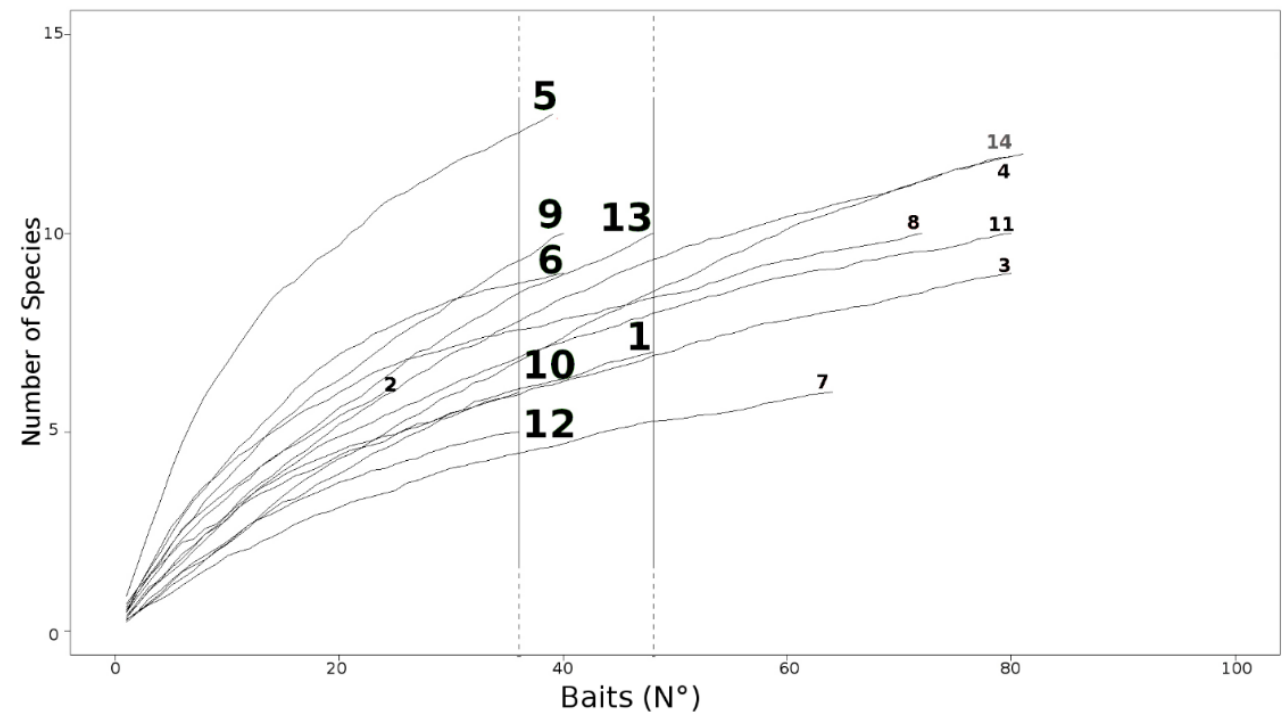

Figure 3. Species accumulation curves of each sites, calculated using the FDataset. Vertical lines show the range of baits (36-48) chosen for creating the StdDataset. The numbers refer to sites according to the list in Table 1.

The NMDS analysis on sampling sites showed the presence of 3 clusters (stress value $=0.18$, $\mathrm{R}^{2}=0.815, p=0.002$ ) (Figure 5). Sites were then located in a map and clusters were shown with different colors (Figure 6).

Species richness, biodiversity indices, and Sorensen index are reported in Table 3. NMDS clusters differed in species richness, biodiversity indices, and in their most frequently collected species. There is an increasing gradient from cluster 1 to cluster 3 for both species' richness and all the biodiversity indices. Similarity index values were similar among sites ranging from 0.35 to 0.50 (Table 3 and Table S3). 


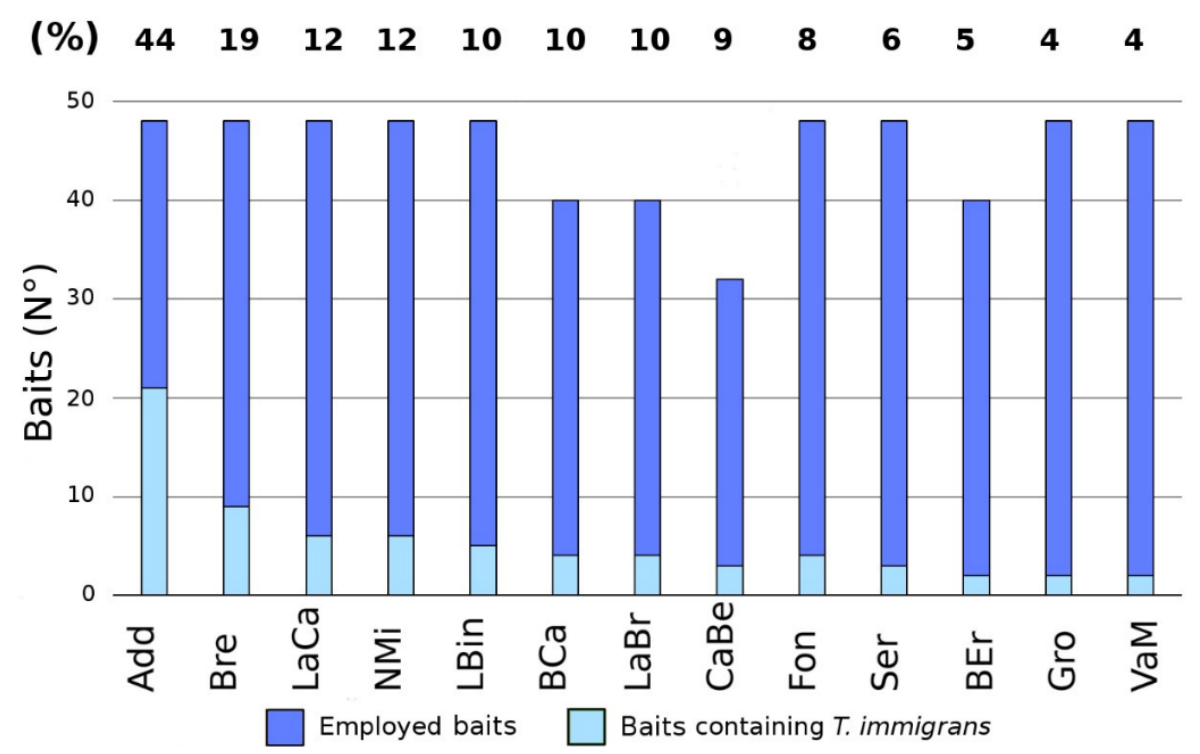

Figure 4. Occurrence of Tetramorium immigrans in each site (StdDataset). The percentage (\%) of baits containing T. immigrans is indicated on top of each bar.

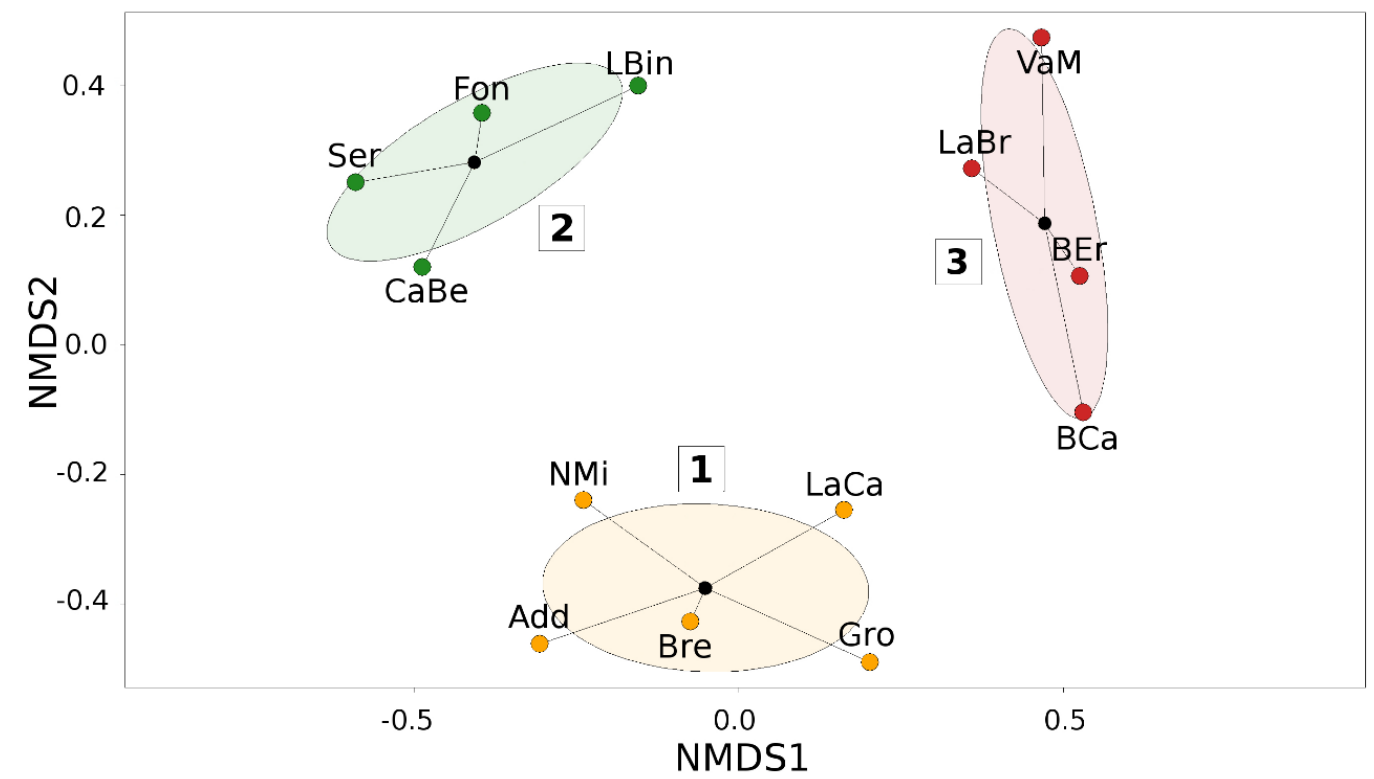

Figure 5. Nonlinear Multidimensional Scaling of the sites according to the average number of baits in which each species was found (StdDataset). Clusters are marked with different colors. For each cluster, ellipses show the standard error and black dots represent the centroids. 
Table 3. Species richness, biodiversity indices, and similarity index of sites. For each Nonmetric Multidimensional Scaling (NMDS) cluster, mean values are listed (StdDataset).

\begin{tabular}{|c|c|c|c|c|c|c|c|c|c|c|}
\hline $\begin{array}{l}\text { NMDS } \\
\text { Cluster }\end{array}$ & Site & $\begin{array}{l}\text { Altitude (m } \\
\text { a.s.l.) }\end{array}$ & $\begin{array}{l}\text { Most Frequent Species and \% of } \\
\text { Occupied Baits }\end{array}$ & N Kits & N Baits & $\begin{array}{l}\text { Species } \\
\text { Richness }\end{array}$ & $\begin{array}{c}\text { Simpson } \\
\text { Diversity } \\
\text { Index (1-D) }\end{array}$ & $\begin{array}{c}\text { Shannon } \\
\text { Diversity } \\
\text { Index }\left(H^{\prime}\right)\end{array}$ & $\begin{array}{c}\text { Species } \\
\text { Equitability } \\
\text { Index (EH) }\end{array}$ & $\begin{array}{c}\text { Sørensen-Dice } \\
\text { Similarity Index } \\
\text { (Average) }\end{array}$ \\
\hline \multirow{6}{*}{ Cluster 1} & Add & 95 & T. immigrans. $(43 \%)$ & 6 & 48 & 7 & 0.76 & 1.67 & 0.86 & 0.50 \\
\hline & Gro & 215 & L. niger $(10 \%)$ & 6 & 48 & 10 & 0.87 & 2.18 & 0.95 & 0.43 \\
\hline & $\mathrm{NMi}$ & 140 & T. immigrans (12\%) & 6 & 48 & 5 & 0.68 & 1.36 & 0.84 & 0.41 \\
\hline & $\mathrm{LaCa}$ & 245 & L. niger/Timmigrans $(12 \%)$ & 4 & 36 & 6 & 0.80 & 1.70 & 0.95 & 0.45 \\
\hline & Bre & 175 & T. immigrans $(18 \%)$ & 6 & 48 & 6 & 0.76 & 1.59 & 0.89 & 0.46 \\
\hline & Mean & 174 & & 5.6 & 45.6 & 6.8 & 0.77 & 1.70 & 0.90 & 0.45 \\
\hline \multirow{5}{*}{ Cluster 2} & Ser & 110 & M. rubra $(6 \%)$ & 6 & 48 & 6 & 0.79 & 1.68 & 0.93 & 0.39 \\
\hline & LBin & 20 & M. monomorium (12\%) & 6 & 48 & 8 & 0.83 & 1.91 & 0.92 & 0.35 \\
\hline & $\mathrm{CaBe}$ & 245 & M. sabuleti $(12 \%)$ & 4 & 36 & 5 & 0.74 & 1.46 & 0.91 & 0.39 \\
\hline & Fon & 30 & M. monomorium (14\%) & 6 & 48 & 10 & 0.84 & 2.06 & 0.89 & 0.41 \\
\hline & Mean & 101 & & 5.5 & 45 & 7.2 & 0.80 & 1.78 & 0.91 & 0.38 \\
\hline \multirow{5}{*}{ Cluster 3} & $\mathrm{BCa}$ & 395 & L. emarginatus (15\%) & 5 & 40 & 14 & 0.90 & 2.46 & 0.93 & 0.50 \\
\hline & $\mathrm{BEr}$ & 845 & L. emarginatus $(10 \%)$ & 5 & 40 & 9 & 0.87 & 2.11 & 0.96 & 0.43 \\
\hline & $\mathrm{LaBr}$ & 380 & L. emarginatus/T. immigrans (10\%) & 5 & 40 & 9 & 0.86 & 2.10 & 0.95 & 0.47 \\
\hline & $\mathrm{VaM}$ & 340 & A. subterranea/T. unifasciatus $(6 \%)$ & 6 & 48 & 11 & 0.89 & 2.29 & 0.96 & 0.41 \\
\hline & Mean & 490 & & 5.2 & 42 & 10.7 & 0.88 & 2.24 & 0.95 & 0.45 \\
\hline
\end{tabular}




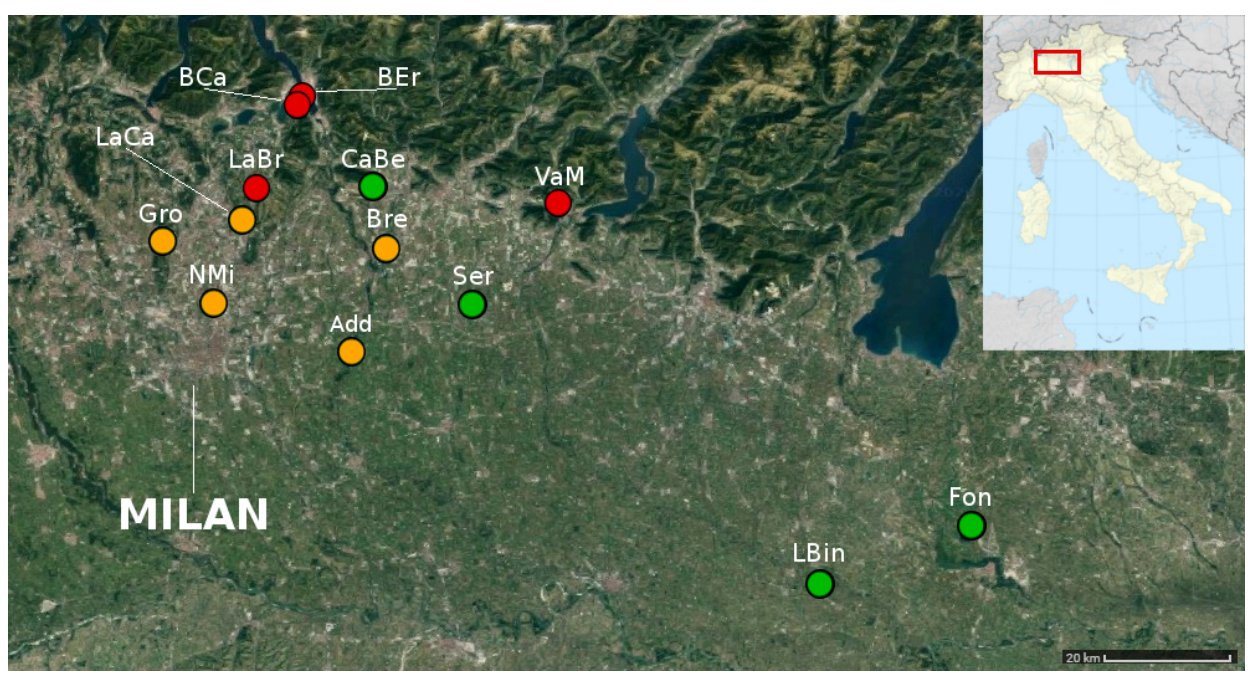

Figure 6. Spatial distribution of sampling sites (StdDataset). Each dot represents a site. Colors correspond to the clusters found in the NMDS analysis: cluster 1-orange, cluster 2-green, and cluster 3-red. Map: satellite image from Google Maps retrieved on 1 March 2020 and modified by authors.

\section{Discussion}

The "School of Ants" and the "BioBlitz Lombardia" are two Citizen Science projects currently operating in Italy. The SoA project aims to analyze the distribution of Italian ant fauna in urban environments for collecting information about the effects of human impact on urban biodiversity, and acting, at the same time, as a tool to introduce the volunteers to scientific research thorough a hand-on experience. The main goal of BBL is promoting the biodiversity of the protected areas in Lombardy through the active participations of volunteers that, helping in recording data, can understand and enhance the value of biodiversity and the importance of containing its lost. The collaboration between the two projects during BBL 2018 was successful in many aspects. The SoA project was opened to new type of volunteers contributing to expand the number of sampling sites and consequently, the database of the identified species. The checklist of urban ants sampled through the SoA project in Italy increased remarkably, helping to fill the knowledge gap on Italian ant species distribution that is one of the main goals of the project. Networking is a very strong value of the BBL: in Italy, this is one of the few examples where a huge effort in coordinating activities of very different participants has been done to support and promote a common vision. BBL found in ants a suitable zoological taxon to be transversally investigated and so improving cohesion among the several protected areas working in the project.

Applying the SoA protocol proved to be remarkably cost-effective for achieving a first quantitative list of ant species in the sampled sites. We were able to detect a relatively high number of different taxa and to provide some key information over the ant communities of the investigated sites, although the sampling effort was limited to just 2 days and to a single methodology (which is obviously unlikely to detect strictly arboreal, endogean, or insectivorous ants).

However, a nonhomogeneous sampling effort forced us to reduce the database with an unavoidable loss of information. This aspect was probably underestimated during the training workshop for park executives led by the SoA researchers. From experiences with school teachers, a particular attention was devoted to the sampling protocol and to the identification of sampling sites, but concepts related to sampling effort were overlooked. Our experience suggests that whenever new figures between researchers and volunteers, such as park executives, are involved, their training is a crucial step and additional efforts need to be done in order to test their effective understanding of the goals and the methods of the project. 
Even though the aim of this research was far from obtaining an exhaustive checklist of the investigated areas, the resulting data represent a valuable contribute to the general knowledge of the region: quantitative surveys on the Po Plain ant fauna are still lacking, and existing faunistic data are scattered across an outdated literature (see [62]). Biogeographically, according to the available species distribution information [64,72,73], Eurasian or European species characterized by considerably wide distribution ranges appeared to be prevalent: roughly one-third of the species (e.g., F. clara, F. cunicularia, L. niger, L. fuliginosus, M. rubra, M. specioides) could be referred to the ASE chorotype and another third (e.g., C. ligniperda, M. sabuleti, L. paralienus, T. caespitum, T. nylanderi, T. parvulus) to the EUR chorotype [74]. The rest of the species are characterized by smaller distribution ranges, gravitating around Southern Europe (F. gagates, M. ibericus, M. monomorium, T. lichtensteini), South-Western Europe (P. pallidula), South-Eastern Europe (M. hellenica, T. flavicornis), the Western-Mediterranean (C. scutellaris), or were circum-Mediterranean (C. lateralis). However, no endemic taxa were found. The overall prevalence of a Central-European fauna, mixed with wide-range South-European species and only limited Mediterranean elements matches our expectation from a Southern-European region characterized by continental climatic conditions and biogeographically equally related to the Eastern and Western Mediterranean sectors (see [75]). Finally, all detected Myrmica spp. represent potential hosts for endangered Phengaris Doherty, 1891 lycaenid butterflies [76,77], that are present in Northern Italy and were recorded in some of the investigated parks (e.g., $[78,79])$.

Although sampling in the most anthropogenic spots of each park, as the SoA protocol demanded, could lead to a strong homogenization of data, the level of detail we achieved was sufficient to highlight a quite clear separation of the sampling sites into three groups. In the first group, L. niger and T. immigrans were the most abundant species. Both are disturbance-tolerant taxa particularly well known to adapt successfully to urban environments [64] and, interestingly, this group is made of lowland sites geographically closely related to the large Milan metropolitan area. In the second group, Myrmica spp. and M. monomorium, ecologically linked to meadows, were prevalent. Sites of the second group are averagely more distant from the metropolitan area and closer to areas where agricultural land use prevails. Finally, in the third group, the most abundant species were L. emarginatus and A. subterranea, usually encountered in broad-leaved woodlands. Sites of this group are located at the foothills of the pre-Alps, in which more natural conditions occur. A more detailed investigation on the relationship between these ecological conditions and the composition of investigated ant communities is beyond the scope of the present paper. However, these indications once again highlight the potential of ant communities as bioindicators, still little explored in Italy [39-44].

Another interesting result was the evidence of T. immigrans ubiquity: although only prevalent in the sites closer to the metropolitan area, it was also the only species found in all of the sampling sites. The T. caespitum complex, to which T. immigrans belongs, was until recently considered to be represented by a single species in Europe. However, it is now considered a cryptic complex of 10 different taxa in the region whose distribution data are often scarce $[53,54,80]$. Among the species of this complex, only T. immigrans is known to possess a notable invasive potential, as it has colonized large areas of North America, gaining since the 19th century the nickname of "pavement" ant due to its extreme success in urban environment (e.g., [81-84]). Tetramorium immigrans is certainly native in the Anatolia and Caucasus regions, where it shows a comparatively high haplotype diversity and inhabits natural mountain habitats $[53,85]$. On the other hand, it appears to be exotic at least in some regions of Europe, where its haplotype diversity is much lower (comparable to North America, see [53]) and, as most introduced ant species (see [86]), it is mainly concentrated in urbanized areas [49,53,87-94]. For example, this situation led to the idea that T. immigrans is an introduced species in both Denmark and Greece $[53,90]$. In these cases, unlike in North America, T. immigrans does not enjoy the easy taxonomic recognition that the numerous other introduced Tetramorium spp. have in Europe; instead, due to the existence of several native cryptic species, it can be classified as a cryptic alien [95]. This whole figure appears somewhat similar to that of L. neglectus Van Loon, Boomsma, and Andrasfalvy, 1990, introduced 
from Anatolia to Europe (from Greece West to Iberia) about 20 years before being taxonomically recognized [64].

In Italy, the situation appears very similar. In Sicily, T. immigrans corresponds to the species about 20 years ago described as a recent colonizer, large species exclusively thriving in severely altered habitats, and named as "Tetramorium caespitum," living spatially segregated from the other species of the complex, which are exclusively montane on the island $[89,94,96]$. When the cryptic complex was taxonomically revised, species identification of the specimens from about 95 Italian localities was provided [53]. Across the six species existing in Italy, the number of urban or near-urban localities for each taxon was about $0 \%$ in the case of T. alpestre Steiner, Schlick-Steiner, and Seifert, $2010(\mathrm{~N}=22)$, T. caespitum $(\mathrm{N}=46)$, T. impurum (Foerster, 1850) $(\mathrm{N}=4)$, and T. indocile Santschi, $1927(\mathrm{~N}=3)$ and 33\% for the Italian endemic T. fusciclava Consani and Zangheri, $1952(\mathrm{~N}=6)$, whereas $100 \%$ for T. immigrans $(\mathrm{N}=14)$ (Wagner et al. 2017). It is remarkable that about $80 \%$ of the sampling sites reported by Wagner and colleagues [53] was in natural or seminatural environments and T. immigrans was never collected there. To better understand the status of T. immigrans in Italy and Europe, more detailed phylogeographic data (see also [84]) and even greater sampling efforts in natural habitats could be meaningful. However, there is currently no evidence suggesting to consider T. immigrans as native to the Po Plain or other Italian regions. Eventual proofs of a quick-post glacial expansion to Europe (justifying the genetic pattern shown in [53]) and of the presence of significant populations in undisturbed habitats of the country would be required to support the latter hypothesis. Until then, we suggest to consider T. immigrans as probably introduced in Italy similarly to the interpretations formulated in other European countries.

In the Po Plain, our data seem to testify a very different situation from Southern Italy, and possibly, quite similar to Southern France: T. immigrans distribution admixes with that of T. caespitum, forming a continuum across an ecological gradient. In France, this situation led to significant hybridization and introgression rates in the contact zone, which may seriously increase identification errors [97]. Moreover, it may suggest that strict proximity between the two species is a recent situation as stronger reproductive barriers would otherwise be expected. Future investigations in Italy could try to test for the existence of similar patterns. Moreover, the present data suggest that $T$. immigrans may be extremely common across Italian urban areas, despite being unnoticed until very recently. This result was only possible thanks to a tight collaboration between citizens and researchers, in which the role of citizens was fundamental to collect a large and valuable number of specimens in a relatively small period of time and the role of researchers was crucial due to the difficult procedures required for species identification.

\section{Conclusions}

Public engagement in biodiversity monitoring can be very useful to track the spread of exotic species, as already demonstrated in few other cases in Italy [98-104]. Current information over the distribution of the probably exotic T. immigrans in Italy remains scarce [62], but our data suggest that it is very common and widespread in disturbed habitats. Moreover, through a vast public involvement, the SoA protocol can be a powerful tool to track the distribution of this species across the country, allowing to quickly gather a significant amount of data from wide geographic areas and urban environments in particular. Since the latter are the most affected by the increasing presence of new exotic ant species [86], the SoA project may also provide more effective early-detection capabilities for the future. The possibilities offered by the use of ants for urban ecological surveys and biodiversity monitoring of disturbed sites appear still largely unchecked, but highly promising.

Supplementary Materials: The following are available online at http://www.mdpi.com/2075-4450/11/10/678/s1, Table S1: List of the 12 parks of the A.R.E.A. Parchi network involved in the project, Table S2: Species checklist according to sites, Table S3: Values of Sørensen-Dice Similarity Index for all the possible comparisons between parks (StdDataset). 
Author Contributions: Conceptualization, C.C. and F.A.S.; methodology, C.C., F.A.S., and E.S.; validation, C.C., F.A.S., E.S., A.M., and D.A.G.; formal analysis, C.C. and E.S.; investigation, C.C., F.A.S., and M.G.; resources, C.C., F.A.S., M.G., and D.G.; data curation, C.C., F.A.S., E.S., and D.G.; writing-original draft preparation, E.S., C.C., and F.A.S.; writing-review and editing, C.C., F.A.S., E.S., D.G., M.G., D.A.G., and A.M.; visualization, C.C., E.S., and F.A.S.; supervision, A.M. and D.A.G.; project administration, C.C. and F.A.S.; funding acquisition, A.M. and D.A.G. All authors have read and agreed to the published version of the manuscript.

Funding: This work was supported by the project agreement "LA SCHOOL OF ANTS AL BIOBLITZ LOMBARDIA 2018" between University of Parma and Parco Nord Milano and grants from the University of Parma (FIL-2018) assigned to D.A.G. and A.M. The work also benefited from the equipment and framework of the COMP-HUB Initiative, funded by the "Departments of Excellence" program of the Italian Ministry for Education, University and Research (MIUR, 2018-2022).

Acknowledgments: We thank Regione Lombardia and A.R.E.A. Parchi administration for supporting the project. We are grateful to all the personnel of the parks (representatives and operators) for the realization of the project during BBL 2018 and to all the citizens that helped us to collect data. We are particularly grateful to Francesco Cecere and Lella Rossetti for involving us in the BBL project. Finally, we thank Valentina Canali for working with us as a part of her university internship.

Conflicts of Interest: The authors declare no conflict of interest.

\section{References}

1. Bonney, R.; Ballard, H.; Jordan, R.; McCallie, E.; Phillips, T.; Shirk, J.; Wildermann, C.C. Public Partecipation in Scientific Research. In Defining the Field and Assessing its Potential for Informal Science Education; A CAISE Inquiry Group Report; Center for Advancement of Informal Science Education (CAISE): Washington, DC, USA, 2009.

2. Bonne, R.; Cooper, C.B.; Dickinson, J.; Kelling, S.; Phillips, T.; Rosenberg, K.V.; Shirk, J. Citizen science: A developing tool for expanding science knowledge and scientific literacy. Bioscience 2009, 59, 977-984. [CrossRef]

3. Follett, R.; Strezov, V. An analysis of citizen science based research: Usage and publication patterns. PLoS ONE 2015, 10, e0143687. [CrossRef] [PubMed]

4. McKinley, D.C.; Miller-Rushing, A.J.; Ballard, H.L.; Bonney, R.; Brown, H.; Cook-Patton, S.C.; Evans, D.M.; French, R.A.; Parrish, J.K.; Phillips, T.B.; et al. Citizen science can improve conservation science, natural resource management and environmental protection. Biol. Conserv. 2017, 208, 15-28. [CrossRef]

5. Dickinson, J.L.; Shirk, J.; Bonter, D.; Bonney, R.; Crain, R.L.; Martin, J.; Phillips, T.; Purcell, K. The current state of citizen science as a tool for ecological research and public engagement. Front. Ecol. Environ. 2012, 10, 291-297. [CrossRef]

6. Tulloch, A.I.; Possingham, H.P.; Joseph, L.N.; Szabo, J.; Martin, T.G. Realising the full potential of citizen science monitoring programs. Biol. Conserv. 2013, 165, 128-138. [CrossRef]

7. Chandler, M.; See, L.; Copas, K.; Bonde, A.M.; López, B.C.; Danielsen, F.; Rosemartin, A. Contribution of citizen science towards international biodiversity monitoring. Biol. Conserv. 2017, 213, 280-294. [CrossRef]

8. Canter, E. Why We are Changing "Citizen Science" to "Community Science". 2019. Available online: https: //gsmit.org/why-we-are-changing-citizen-science-to-community-science/ (accessed on 3 September 2020).

9. Natural History Museum of Los Angeles County. Why Community Science. Available online: https: //nhmlac.org/community-science-nhm/why-community-science (accessed on 3 September 2020).

10. UNESCO. Preliminary study of the technical, financial and legal aspects of the desirability of a UNESCO recommendation on Open Science. In UNESCO General Conference, 40th. Paris, France, 8 October 2019; 2019; pp. 1-24. Available online: https://unesdoc.unesco.org/ark:/48223/pf0000370291 (accessed on 3 September 2020).

11. Wehn, U.; Göbel, C.; Bowser, A.; Hepburn, L.; Haklay, M. Global Citizen Science Perspectives on Open Science. 2020, pp. 1-30. Available online: https://mfr.de1.osf.io/render?url=https://osf.io/6qjyg/?direct\% 26 mode $=$ render $\% 26$ action $=$ download $\% 26$ mode $=$ render (accessed on 3 September 2020).

12. Charles, A.; Loucks, L.; Berkes, F.; Armitage, D. Community science: A typology and its implications for governance of social-ecological systems. Environ. Sci. Policy 2020, 106, 77-86. [CrossRef]

13. U.N. General Assembly Transforming Our World: The 2030 Agenda for Sustainable Development. In Proceedings of the Seventieth Session of the General, New York, NY, USA, 25 September 2015. 
14. Bio Innovation Service. Citizen Science for Environmental Policy: Development of an EU-Wide Inventory and Analysis of Selected Practices; Final Report for the European Commission, DG Environment under the contract 070203/2017/7668879/ETU/ENV.A.3; Publications Office of the European Union: Luxembourg, 2018.

15. Fraisl, D.; Campbell, J.; See, L.; When, U.; Wardlaw, J.; Gold, M.; Moorthy, I.; Arias, R.; Piera, J.; Oliver, J.L.; et al. Mapping citizen science contributions to the UN sustainable development goals. Sustain. Sci. 2020. [CrossRef]

16. Theobald, E.J.; Ettinger, A.K.; Burgess, H.K.; DeBey, L.B.; Schmidt, N.R.; Froehlich, H.E.; Wagner, C.; HilleRisLambers, J.; Tewsbury, J.; Harsch, M.A.; et al. Global change and local solutions: Tapping the unrealized potential of citizen science for biodiversity research. Biol. Conserv. 2015, 181, 236-244. [CrossRef]

17. Díaz, S.; Settele, J.; Brondízio, E.; Ngo, H.; Guèze, M.; Agard, J.; Arneth, A.; Balvanera, P.; Brauman, K.; Butchart, S.; et al. Summary for Policymakers of the Global Assessment Report on Biodiversity and Ecosystem Services of the Intergovernmental Science-Policy Platform on Biodiversity and Ecosystem Services; IPBES Secretariat: Bonn, Germany, 2020.

18. Devictor, V.; Whittaker, R.J.; Beltrame, C. Beyond scarcity: Citizen science programmes as useful tools for conservation biogeography. Divers. Distrib. 2010, 16, 354-362. [CrossRef]

19. Tweddle, J.C.; Robinson, L.D.; Pocock, M.J.O.; Roy, H.E. Guide to Citizen Science: Developing, Implementing and Evaluating Citizen Science to Study Biodiversity and the Environment in the UK; Natural History Museum: London, UK; Centre for Ecology and Hydrology of the UK Environmental Observation Center: Lancaster, UK, 2012.

20. Pocock, M.J.O.; Chapman, D.S.; Sheppard, L.J.; Roy, H.E. Choosing and Using Citizen Science: A Guide to when and how to Use Citizen Science to Monitor Biodiversity and the Environment; NERC Centre for Ecology and Hydrology: Wallingford, UK, 2014.

21. Birkin, L.; Goulson, D. Using citizen science to monitor pollination services. Ecol. Entomol. 2015, 40, 3-11. [CrossRef]

22. Hölldobler, B.; Wilson, E.O. The Ants; Harvard University Press: Cambridge, MA, USA, 1990.

23. Agosti, D.; Majer, J.D.; Alonso, L.E.; Schultz, T.R. Standard Methods for Measuring and Monitoring Biodiversity; Smithsonian Institution: Washington, DC, USA, 2000.

24. Lach, L.; Lori, L.; Parr, L.; Catherine, L.; Abbot, K. Ant Ecology; Oxford University Press: Oxford, UK, 2010.

25. Del Toro, I.; Ribbons, R.R.; Pelini, S. The little things that run the world revisited: A review of ant-mediated ecosystem services and disservices (Hymenoptera: Formicidae). Myrmecol. News 2012, 17, 133-146.

26. Gibb, H.; Sanders, N.J.; Dunn, R.R.; Watson, S.; Photakis, M.; Abril, S.; Andersen, A.N.; Angulo, E.; Armbrecht, I.; Arnan, X.; et al. Climate mediates the effects of disturbance on ant assemblage structure. Proc. R. Soc. B Biol. Sci. 2015, 282, 20150418. [CrossRef] [PubMed]

27. Arnan, X.; Andersen, A.N.; Gibb, H.; Parr, C.L.; Sanders, N.J.; Dunn, R.R.; Angulo, E.; Baccaro, F.B.; Bishop, T.R.; Boulay, R.; et al. Dominance-diversity relationships in ant communities differ with invasion. Glob. Chang. Biol. 2018, 24, 4614-4625. [CrossRef] [PubMed]

28. Tibcherani, M.; Nacagava, V.A.F.; Aranda, R.; Mello, R.L. Review of Ants (Hymenoptera: Formicidae) as bioindicators in the Brazilian Savanna. Sociobiology 2018, 65, 112-129. [CrossRef]

29. Elizalde, L.; Arbetman, M.; Arnan, X.; Eggleton, P.; Leal, I.R.; Lescano, M.N.; Saez, A.; Werenkraut, V.; Pirk, G.I. The ecosystem services provided by social insects: Traits, management tools and knowledge gaps. Biol. Rev. 2020. [CrossRef] [PubMed]

30. Kowarik, I. Novel urban ecosystems, and conservation. Environ. Pollut. 2011, 159, 1974-1983. [CrossRef]

31. Beninde, J.; Veith, M.; Hochkirch, A. Biodiversity in cities needs space: A meta-analysis of factors determining intra-urban biodiversity variation. Ecol. Lett. 2015, 18, 581-592. [CrossRef]

32. Aronson, M.F.J.; Lepczyk, C.A.; Evans, K.L.; Goddard, M.A.; Lerman, S.B.; MacIvor, J.S.; Nilon, C.H.; Vargo, T. Biodiversity in the city: Key challenges for urban green space management. Front. Ecol. Environ. 2017, 15, 189-196. [CrossRef]

33. Angiletta, M.J.; Wilson, R.S.; Niehaus, A.C.; Sears, M.W.; Navas, C.A.; Ribeiro, P.L. Urban Physiology: City Ants Possess High Heat Tolerance. PLoS ONE 2007, 2, e258. [CrossRef]

34. Clarke, K.M.; Fisher, B.L.; LeBuhn, G. The influence of urban park characteristics on ant (Hymenoptera, Formicidae) communities. Urban Ecosyst. 2008, 11, 317-334. [CrossRef]

35. Pećarević, M.; Danoff-Burg, J.; Dunn, R.R. Biodiversity on Broadway-enigmatic diversity of the societies of ants (Formicidae) on the streets of New York City. PLoS ONE 2010, 5, e13222. [CrossRef] [PubMed] 
36. Menke, S.B.; Guénard, B.; Sexton, J.O.; Weiser, M.D.; Dunn, R.R.; Silverman, J. Urban areas may serve as habitat and corridors for dry-adapted, heat tolerant species; an example from ants. Urban Ecosyst. 2011, 14, 135-163. [CrossRef]

37. Chick, L.D.; Strickler, S.A.; Perez, A.; Martin, R.A.; Diamond, S.E. Urban heat islands advance the timing of reproduction in a social insect. J. Therm. Biol. 2019, 80, 119-125. [CrossRef] [PubMed]

38. Nooten, S.S.; Schultheiss, P.; Rowe, R.C.; Facey, S.L.; Cook, J.M. Habitat complexity affects functional traits and diversity of ant assemblages in urban green spaces (Hymenoptera: Formicidae). Myrmecol. News 2019, $29,67-77$.

39. Castracani, C.; Mori, A. The role of permanent grasslands on ant community structure: Ants (Hymenoptera: Formicidae) as ecological indicators in the agro-ecosystems of the Taro River Regional Park (Italy). Myrmecol. Nachr. 2006, 9, 47-54.

40. Castracani, C.; Piotti, A.; Grasso, D.A.; Le Moli, F.; Mori, A. Ant fauna as ecological indicator in Italian agroecosystems. Redia 2007, 90, 67-70.

41. Castracani, C.; Grasso, D.A.; Fanfani, A.; Mori, A. The ant fauna of Castelporziano Presidential Reserve (Rome, Italy) as a model for the analysis of ant community structure in relation to environmental variation in Mediterranean ecosystems. J. Insect Conserv. 2010, 14, 585-594. [CrossRef]

42. Ottonetti, L.; Tucci, L.; Frizzi, F.; Chelazzi, G.; Santini, G. Changes in ground-foraging ant assemblages along a disturbance gradient in a tropical agricultural landscape. Ethol. Ecol. Evol. 2010, 22, 73-86. [CrossRef]

43. Spotti, F.A.; Castracani, C.; Grasso, D.A.; Fanfani, A.; Mori, A. The community structure temporal development of Castelporziano ant fauna. Redia 2010, 89-93.

44. Satta, A.; Verdinelli, M.; Ruiu, L.; Buffa, F.; Salis, S.; Sassu, A.; Floris, I. Combination of beehive matrices analysis and ant biodiversity to study heavy metal pollution impact in a post-mining area (Sardinia, Italy). Environ. Sci. Pollut. Res. 2012, 19, 3977-3988. [CrossRef] [PubMed]

45. Lucky, A.; Dunn, R.R.; School of Ants. A Your wildilife.org Project. Available online: http://schoolofants.org/ (accessed on 1 August 2020).

46. Lucky, A.; Savage, A.M.; Nichols, L.M.; Castracani, C.; Shell, L.; Grasso, D.A.; Mori, A.; Dunn, R.R. Ecologists, educators, and writers collaborate with the public to assess backyard diversity in The School of Ants Project. Ecosphere 2014, 5. [CrossRef]

47. Castracani, C.; Spotti, F.A. School of Ants: A Scuola con le Formiche. Available online: http://www. schoolofants.it/ (accessed on 1 August 2020).

48. Abbott, C. School of Ants Australia. Available online: http://www.schoolofants.net.au/ (accessed on 1 August 2020).

49. Sheard, J.K.; Sanders, N.J.; Gundlach, C.; Schär, S.; Larsen, R.S. Monitoring the influx of new species through citizen science: The first introduced ant in Denmark. Peer] 2020, 8, e8850. [CrossRef] [PubMed]

50. OECD. Education at a Glance 2017: OECD Indicators; OECD Publishing: Paris, France, 2017.

51. OECD. Pisa 2018 Results (Volume I): What Students Know and can Do; OECD Publishing: Paris, France, 2019.

52. MUSE Science Museum/Museo delle Scienze. Available online: https://www.muse.it/it/Pagine/default.aspx (accessed on 1 August 2020).

53. Wagner, H.C.; Arthofer, W.; Seifert, B.; Muster, C.; Steiner, F.M.; Schlick-Steiner, B.C. Light at the end of the tunnel: Integrative taxonomy delimits cryptic species in the Tetramorium caespitum complex (Hymenoptera: Formicidae). Myrmecol. News 2017, 25, 95-129.

54. Wagner, H.C.; Gamisch, A.; Arthofer, W.; Moder, K.; Steiner, F.M.; Schlick-Steiner, B.C. Evolution of morphological crypsis in the Tetramorium caespitum ant species complex (Hymenoptera: Formicidae). Sci. Rep. 2018, 8, 12547. [CrossRef]

55. BioBlitz Lombardia. Available online: http://www.areaparchi.it/pagina.php?id=3 (accessed on 1 August 2020).

56. Regione Lombardia. Available online: https://www.regione.lombardia.it/wps/portal/istituzionale/ (accessed on 1 August 2020).

57. Lundmark, C. BioBlitz: Getting into backyard biodiversity. Bioscience 2003, 53, 329. [CrossRef]

58. Robinson, L.D.; Tweddle, J.C.; Postles, M.C.; West, S.E.; Sewell, J. Guide to Running a BioBlitz; Natural History Museum: London, UK; Bristol Natural History Consortium: Bristol, UK; Stockholm Environment Institute: York, UK; Marine Biological Association: Plymouth, UK, 2013. 
59. DITOs Consortium. BioBlitz: Promoting Cross Border Research and Collaborative Practices for Biodiversity Conservation. Dito Policy Brief 1; UCL (University College London): London, UK, 2017.

60. iNaturalist-BioBlitz Lombardia 2018. Available online: https:/www.inaturalist.org/projects/bioblitzlombardia-2018/ (accessed on 1 August 2020).

61. ECSA. Ten Principles of Citizen Science. Available online: https://ecsa.citizen-science.net/documents (accessed on 1 August 2020).

62. Baroni Urbani, C. Catalogo delle specie di Formicidae d'Italia. Mem. Soc. Entomol. Ital. 1971, 50, 5-287.

63. Radchenko, A.G.; Elmes, G.W. Myrmica Ants of the Old World; Natura Optima Dux Foundation: Warsaw, Poland, 2010.

64. Seifert, B. The Ants of Central and Northern Europe; Lutra Verlags- und Vertriebsgesellschaft: Tauer, Germany, 2018.

65. Seifert, B.; Galkowski, C. The Westpalaearctic Lasius paralienus complex (Hymenoptera: Formicidae) contains three species. Zootaxa 2016, 4132, 44-58. [CrossRef] [PubMed]

66. R Core Team. R: A Language and Environment for Statistical Computing; R Foundation for Statistical Computing: Vienna, Austria, 2019. Available online: https://www.R-project.org/ (accessed on 1 August 2020).

67. Oksanen, J.; Blanchet, F.G.; Friendly, M.; Kindt, R.; Legendre, P.; McGlinn, D.; Minchin, P.R.; O’Hara, R.B.; Simpson, G.L.; Solymos, P.; et al. Vegan: Community Ecology Package. R Package Version 2.5-6. 2019. Available online: https://cran.r-project.org/package=vegan (accessed on 1 August 2020).

68. Shannon, C. A mathematical theory of communication. Bell. Syst. Tech. 1948, 27, 379-423. [CrossRef]

69. Simpson, E.H. Measurement of diversity. Nature 1949, 163, 688. [CrossRef]

70. Dice, L.R. Measurement of the amount of Ecological Association between Species. Ecology 1945, 26, $297-302$. [CrossRef]

71. Sørensen, T. A Method for Establishing Groups of Equal Amplitude in Plant Sociology Based on Similarity of Species Content. Biol. Skr. K. Dan. Vidensk. Pollut. 1949, 1, 3-34.

72. Guénard, B.; Weiser, M.; Gomez, K.; Narula, N.; Economo, E.P. The Global Ant Biodiversity Informatics (GABI) database: A synthesis of ant species geographic distributions. Myrmecol. News 2017, 24, 83-89.

73. Janicki, J.; Narula, N.; Ziegler, M.; Guénard, B.; Economo, E.P. Visualizing and interacting with large-volume biodiversity data using client-server web-mapping applications: The design and implementation of antmaps.org. Ecol. Inform. 2016, 32, 185-193. [CrossRef]

74. Vigna Taglianti, A.; Audisio, P.A.; Biondi, M.; Bologna, M.A.; Carpaneto, G.M.; De Biase, A.; Fattorini, S.; Piattella, E.; Sindaco, R.; Venchi, A.; et al. A proposal for a chorotype classification of the Near East fauna, in the framework of the Western Palearctic region. Biogeographia 1999, 20, 31-59. [CrossRef]

75. Schifani, E.; Alicata, A. Aphaenogaster finzii Müller, 1921, a trans-Ionian species new to Italy (Hymenoptera, Formicidae). Biogeographia 2019, 34, 51-57. [CrossRef]

76. Steiner, F.M.; Sielezniew, M.; Schlick-Steiner, B.C.; Höttinger, H.; Stankiewicz, A.; Górnicki, A. Host specificity revisited: New data on Myrmica host ants of the lycaenid butterfly Maculinea Rebeli. J. Insect Conserv. 2003, 7, 1-6. [CrossRef]

77. Pech, P.; Fric, Z.; Konvicka, M. Species-specificity of the Phengaris (Maculinea)-Myrmica host system: Fact or myth? (Lepidoptera: Lycaenidae; Hymenoptera: Formicidae). Sociobiology 2007, 50, 983-1004.

78. Corezzola, S.; Hardersen, S.; Maffezzoli, L. Discovery of isolated populations of Phengaris alcon and of Melitaea diamina in the central Po Plain, Italy (Lepidoptera Rhopalocera). Boll. Soc. Entomol. Ital. 2012, 71-78. [CrossRef]

79. Brusa, G.; Villa, M. Piano di Gestione del Sito di Importanza Comunitaria IT2030003 “Monte Barro" e della Zona di Protezione Speciale IT2030301 “Monte Barro”. 2014. Available online: http://www.parcobarro.it/ (accessed on 1 August 2020).

80. Schlick-Steiner, B.C.; Steiner, F.M.; Moder, K.; Seifert, B.; Sanetra, M.; Dyreson, E.; Stauffer, C.; Christian, E. A multidisciplinary approach reveals cryptic diversity in Western Palearctic Tetramorium ants (Hymenoptera: Formicidae). Mol. Phylogenet. Evol. 2006, 40, 259-273. [CrossRef]

81. McCook, M. Combats and nidification of the pavement ant, Tetramorium caespitum. Proc. Acad. Nat. Sci. Phila. 1879, 31, 156-161. 
82. Bruder, K.W.; Gupta, A.P. Biology of the pavement ant, Tetramorium caespitum (Hymenoptera: Formicidae). Ann. Entomol. Soc. Am. 1972, 65, 358-367. [CrossRef]

83. Antonelli, A.; Glass, J.; Rec, W.P. Pavement ant-An increasingly annoying nuisance pest. Wash. State Univ. Puyallup Res. Ext. Cent. Pest Leafl. Ser. PLS 2006, 19, 1-2.

84. Zhang, Y.M.; Vitone, T.R.; Storer, C.G.; Payton, A.C.; Dunn, R.R.; Hulcr, J.; McDaniel, S.F.; Lucky, A. From Pavement to Population Genomics: Characterizing a Long-Established Non-native Ant in North America Through Citizen Science and ddRADseq. Front. Ecol. Evol. 2019, 7, 453. [CrossRef]

85. Wagner, H.C.; Karaman, C.; Askov, V.; Kiran, K. A mixed colony of Tetramorium immigrans Santschi, 1927 and the putative social parasite Tetramorium aspina sp. n. (Hymenoptera: Formicidae). Myrmecol. News 2018, 28, 25-33.

86. Schifani, E. Exotic Ants Invading Mediterranean Europe: A Brief Summary over about 200 Years of Documented Introductions. Sociobiology 2019, 66, 198-208. [CrossRef]

87. Gippet, J.M.W.; Mondy, N.; Diallo-Dudek, J.; Bellec, A.; Dumpet, A.; Mistler, L.; Kaufmann, B. I'm not like everybody else: Urbanization factors shaping spatial distribution of native and invasive ants are species-specific. Urban Environ. 2017, 20, 157-169. [CrossRef]

88. Borowiec, L.; Salata, S. Notes on the Ants (Hymenoptera: Formicidae) of Euboea Island, Central Greece. Ann. Up. Sil. Mus. (Ent.) 2018, 27, 1-15.

89. Schifani, E.; Alicata, A. Exploring the myrmecofauna of Sicily: Thirty-two new ant species recorded, including six new to Italy and many new aliens (Hymenoptera, Formicidae). Pol. J. Entomol. 2018, 87, 323-348. [CrossRef]

90. Salata, S.; Borowiec, L. Comments on the distribution of several Greek Tetramorium Mayr, 1855 species (Hymenoptera: Formicidae). Ann. Up. Sil. Mus. (Ent.) 2019, 28, 1-9.

91. Cordonnier, M.; Bellec, A.; Dumet, A.; Escarguel, G.; Kaufmann, B. Range limits in sympatric cryptic species: A case study in Tetramorium pavement ants (Hymenoptera: Formicidae) across a biogeographical boundary. Insect Conserv. Diver. 2019, 12, 109-120. [CrossRef]

92. Cordonnier, M.; Gibert, C.; Bellec, A.; Kaufmann, B.; Escarguel, G. Multi-scale impacts of urbanization on species distribution within the genus Tetramorium. Landsc. Ecol. 2019, 34, 1937-1948. [CrossRef]

93. Cordonnier, M.; Bellec, A.; Escarguel, G.; Kaufmann, B. Effects of urbanization-climate interactions on range expansion in the invasive European pavement ant. Basic Appl. Ecol. 2020, 44, 46-54. [CrossRef]

94. Schär, S.; Menchetti, M.; Schifani, E.; Hinojosa, J.C.; Platania, L.; Dapporto, L.; Vila, R. Integrative biodiversity inventory of ants from a Sicilian archipelago reveals high diversity on young volcanic islands (Hymenoptera: Formicidae). Org. Divers. Evol. 2020, 20, 405-416. [CrossRef]

95. Morais, P.; Reichard, M. Cryptic invasions: A review. Sci. Total Environ. 2018, 613, 1438-1448. [CrossRef] [PubMed]

96. Sanetra, M.; Güsten, R.; Schulz, A. On the taxonomy and distribution of Italian Tetramorium species and their social prasites. Mem. Soc. Entomol. Ital. 1999, 77, 317-357.

97. Cordonnier, M.; Gayet, T.; Escarguel, G.; Kaufmann, B. From hybridization to introgression between two closely related sympatric ant species. J. Zool. Syst. Evol. Res. 2019, 57, 778-788. [CrossRef]

98. Maistrello, L.; Dioli, P.; Bariselli, M.; Mazzoli, G.L.; Giacalone-Forini, I. Citizen science and early detection of invasive species: Phenology of first occurrences of Halyomorpha halys in Southern Europe. Biol. Invasions 2016, 18, 3109-3116. [CrossRef]

99. Faraone, F.; Giacalone, G.; Canale, D.; D’Angelo, S.; Favaccio, G.; Garozzo, V.; Giacontieri, G.L.; Isgrò, C.; Melfi, R.; Morello, B.; et al. Tracking the invasion of the red swamp crayfish Procrambarus clarkii (Girad, 1852) (Decapoda Cambarida) in Sicily: A “citizen science" approach. Biogeographia 2017, 32, 25-29.

100. Mori, E.; Baeri, A.; Sforzi, A.; Vitale, A.; Galimberti, A. From accidental citizen-science observations to genetic confirmation: How to spot new hidden invaders. Hystrix 2017, 28, 284-287.

101. Maistrello, L.; Dioli, P.; Dutto, M.; Volani, S.; Pasquali, S.; Giglioli, G. Tracking the spread of sneaking aliens by integrating crodsourcing and spatial modelling: The Italian invasion of Halyomorpha halys. Bioscience 2018, 68, 979-989.

102. Mannino, A.M.; Balistreri, P. Citizen cience: A successful tool for monitoring invasive alien species (IAS) in Marine Protected Areas. The case study of the Egadi Islands MPA (Thyrrenian Sea, Italy). Biodiversity 2018, $18,42-48$. 
103. Schifani, E.; Paolinelli, R. Forums and social media help to discover exotic species in Europe and monitor their spread: The case of Exaireta spinigera (Wiedemann, 1830) (Diptera, Stratiomyidae) in the Italian peninsula and Sicily. Graellsia 2018, 74, e079. [CrossRef]

104. Tiralongo, F.; Crocetta, F.; Riginella, E.; Lillo, A.O.; Tondo, E.; Macali, A.; Mancini, E.; Russo, F.; Coco, S.; Paolillo, G.; et al. Snapshot of rare, exotic and overlooked fish species in the Italian seas: A citizen science survey. J. Sea Res. 2020, 164, 101930. [CrossRef] 